\title{
RESTING ELECTROCARDIOGRAPHIC AND ECHOCARDIOGRAPHIC FINDINGS IN AN URBAN COMMUNITY IN THE GAMBIA
}

\author{
B.C. Nkum ${ }^{1}$, O. Nyan', T. Corrah', T.C. Ankrah ${ }^{1}$, S. Allen ${ }^{2}$, F.B. Micah ${ }^{1}$ and K. McAdam ${ }^{2}$ \\ ${ }^{1}$ Department of Medicine, School of Medical Sciences, \\ Kwame Nkrumah University of Science and Technology, Kumasi, Ghana \\ ${ }^{2}$ Medical Research Council Laboratories, Fajara, Gambia
}

\begin{abstract}
The presence of Left Ventricular Hypertrophy (LVH) in a patient with systemic hypertension deserves serious attention and makes its clinical diagnosis a priority. Over the years various criteria have been proposed for the electrographic (ECG) diagnosis of LVH and the sensitivity and specificity of these criteria have been extensively studied in Caucasians. Recent evidence indicates that they are inapplicable to people of African descent. Unlike echocardiography (ECHO), the ECG is generally available, cheap but has a lower sensitivity in detecting LVH compared to echocardiography. This study was conducted to evaluate ECG criteria against 2-dimensional (2-D) guided M-mode echocardiography in the diagnosis of LVH in adult Gambians. Secondly, to determine the ECG criteria using the Minnesota, Araoye, Sokolow and Lyon or Wolff criteria with the overall best accuracy for the diagnosis of LVH. Two hundred and eight (208) consecutive patients with systemic hypertension (BP $\geq 140 / 90 \mathrm{mmHg}$ ) with or without treatment and an age matched group of 108 non-hypertensive patients were enrolled from outpatient clinics. A questionnaire was filled. All patients were investigated with 2-D guided M-mode echocardiography and a standard 12-1ead ECG. Anthropometric measurements were also taken. The gold standard was the Penn formula to determine the left ventricular mass index (of $125 \mathrm{~g} / \mathrm{m}^{2}$ in males and $110 \mathrm{~g} / \mathrm{m}^{2}$ in females as the cut-off for $\mathrm{LVH}$ ). Using this gold standard the prevalence of echocardiographic $\mathrm{LVH}$ was $47.5 \%$ and $27.8 \%$ in the hypertensives and non-hypertensives respectively $(P<0.01)$. By the Receiver Operating Characteristic (ROC) Curves Sokolow and Lyon was nearest to the top left-hand corner in the hypertensives with a distance of 6.6 cm. But in the non-hypertensives Wolff was nearest to the top left-hand corner with a distance of 8.5 cm. There was correlation between the Minnesota, Araoye, Sokolow and Lyon and Wolff ECG criteria and echocardiographic left ventricular mass index in the hypertensives (Spearman rho $=0.25$ $0.34, P<0.01)$ but in the non-hypertensives there was no correlation $(P>0.05)$. Sokolow and Lyon criterion had overall best accuracy for the electrocardiographic diagnosis of left ventricular hypertrophy in hypertensives and is further recommended for use as such. But for non-hypertensives, the Wolff criterion had overall best accuracy.
\end{abstract}

Keywords: Systemic Hypertension, LVH, ECG, Echocardiogram

130 Journal of Science and Technology, Vol. 29, No. 1, April, 2009 


\section{INTRODUCTION}

Non-communicable diseases (NCDs) are an emerging problem in the developing world (World Development Report, 1993). It has been argued that NCDs will become increasingly important causes of morbidity and mortality in those parts of sub-Saharan Africa (sSA) where life expectancy is increasing, and where increased stress and change in diet and smoking habits are occurring as a result of urbanisation (Feacham et al., 1991; Mosley et al., 1993). Cardiovascular diseases, particularly systemic hypertension, are recognised as important emerging NCDs in the region (Akinkugbe, 1990). Hypertension is rapidly becoming a major public health concern in sub-Saharan Africa (Swai et al., 1993; Kaufman et al., 1993; Amoah, 2003; Cappuccio et al., 2004). Hypertensive target organ damage includes left ventricular hypertrophy (LVH), heart failure, ischaemic heart disease, arrhythmias and sudden death, kidney failure, cerebrovascular accidents, retinopathy and central as well as peripheral vascular disease (Pobee et al., 1977; Akinkugbe, 1990; Plange-Rhule et al., 1999). Previously considered a useful adaptation to chronic pressure overload, left ventricular hypertrophy, which results from hypertension is now established as a powerful, independent predictor of fatal and non-fatal cardiovascular complications and all-cause mortality in both men and women (Levy et al., 1990). In view of its prognostic impact, an argument could be made for the routine assessment of this intermediate end-point in each patient with essential hypertension. LVH is best detected by echocardiography (ECHO). It is expensive and requires technical skills, and available only at the leading hospitals or tertiary health institutions in developing countries. In contrast electrocardiography (ECG) is cheap generally available making it a cost effective diagnostic alternative with which to detect and follow the progression or regression of LVH in hypertensive patients.

Left ventricular hypertrophy is a strong adverse factor for cardiovascular disease. The aims and objectives of the present study are:
- To evaluate ECG criteria against 2dimensional guided M-mode echocardiography in the diagnosis of LVH in adult Gambians

- To determine the ECG criteria (Minnesota, Araoye, Sokolow or Wolff) with the overall best accuracy for the diagnosis of LVH using Penn convention formula as the gold standard.

\section{MATERIALS AND METHODS}

This is a descriptive study conducted at the Royal Victoria Teaching Hospital, Banjul and the Medical Research Council (MRC) Laboratories, Fajara, Gambia. The participants were recruited in four and half months' period (Mid January to May 2000).

Study Population: Patients with systemic hypertension but without (known) diabetes mellitus attending the hypertension clinic at the medical out-patients department of the Royal Victoria Teaching Hospital were recruited consecutively. The clinic notes were verified to ensure that the systolic and /or diastolic blood pressures were equal to or greater than 140 and/or $90 \mathrm{mmHg}$ respectively at least on two separate occasions. The hypertensive subjects were receiving monotherapy or combinations of Bendrofluazide, Methyldopa, Propranolol, Nifedipine, Hydralazine, and Atenolol.

The non-hypertensives recruited were patients attending the Gate Clinic of the MRC Laboratories, Fajara. They were clinically diagnosed as having minor infections (malaria, acute upper respiratory tract infection and acute lower urinary tract infection). They had no cardiovascular disease and they were not diabetics.

All participants were 30 years and above.

Exclusion criteria: Participants with systemic or metabolic diseases, severe inter-current illnesses; cardiovascular disease (excluding hypertension) or labile hypertension were excluded from the study. Morbid obesity with BMI $>35 \mathrm{~kg} / \mathrm{m}^{2}$ because echocardiography may be technically very 
difficult to perform were also excluded from the study.

\section{Questionnaire/Physical Examination}

A questionnaire was administered by a field worker using the appropriate local language. This included items on demography and medical history (for example, hypertension). A physical examination was done by one physician. Details included weight, height and cardiovascular signs including pulse, blood pressure, jugular venous pressure and precordial findings.

\begin{abstract}
Anthropometry
Weight was measured (to the nearest $0.1 \mathrm{~kg}$ ) on electric scales (Secca ${ }^{\mathrm{r}}$ 770, CMS London), with subjects wearing light clothes and without footwear. The height was measured to the nearest 0.5 $\mathrm{cm}$ with footwear and head gear or cap off, using standardised statometers. Hip and waist circumferences were measured using a plastic tape measure. Measurement was recorded to the nearest $0.5 \mathrm{~cm}$.
\end{abstract}

\section{Blood Pressure}

The blood pressure was measured on the left arm (according to manufacture's instructions). The lower arm was supported and the cuff was applied to the upper arm at approximate heart level. The subject was seated for at least five minutes. A standard cuff size $(12 \mathrm{~cm} \times 24 \mathrm{~cm})$ and a validated oscillometric automated digital blood pressure machines (Omron ${ }^{\mathrm{r}} \mathrm{HOM}-705 \mathrm{CP}$, Japan) were used (Hammond et al. 1996). A large cuff $(15 \mathrm{~cm} \times 32 \mathrm{~cm})$, (from the manufacturer) was used for obese subjects whose upper arm circumference exceeded about $33 \mathrm{~cm}$. The lower edge of the cuff was placed at least $2 \mathrm{~cm}$ from the antecubital fossa. Three readings were taken. A first measurement was used to familiarise the subject with the procedure. The blood pressure was repeated twice at five minutes intervals, during which the subject remained seated. The mean of the later two readings was used in the analysis (Mayet et al., 1994). The non-hypertensives had both the systolic and diastolic blood pressures less than 140 and $90 \mathrm{mmHg}$ respectively on 3 separate occasions. The values used in the analysis were the re-check when the subject was booked for ECG 7-14 days later.

\section{Electrocardiography}

The subjects had the ECG recorded using a portable Cardette ${ }^{\mathrm{r}}$ Excel 103 ECG machine. With the subject in the fasting state, lying supine and relaxed on a low pillow, the electrodes were placed as originally described by Frank (Binder, 1961). The stylus control was set at $10 \mathrm{~mm} / \mathrm{mV}$ and paper speed at $25 \mathrm{~mm} / \mathrm{s}$. It was regularly checked for any technical faults such as damping and electrical interference. The parameters used were checked measurements from the machine.

\section{Echocardiography}

A 2-dimensional guided M-mode echocardiography was performed using a $3.5 \mathrm{MHz}$ transducer on Hitachi EUB - 405 ultrasound scanner. The subjects were studied most commonly in the left lateral or partial left lateral position. The transducer was tilted and rotated such that the guiding cursor line (on the 2-D image) was perpendicular to the inter-ventricular septum and the posterior wall to avoid over or under -estimation of the thickness. Left ventricular posterior wall thickness was measured from the endocardial echo to the edge of the acoustic epicardial echo (Attah et al., 1977). The inter-ventricular septum was measured between its endocardial echoes. Distances, time and heart rate were recorded on polaroid paper. The left ventricular end-diastolic diameter (LVEDD) was measured from the leading edge of the anterior endocardium to the leading edge of the posterior wall endocardium at end -diastole. The left ventricular end-systolic diameter (LVESD) was measured from inner edge of the anterior endocardium to the inner edge of the posterior wall endocardium of the left ventricle at end-systole.

To maintain blinding/objectivity between ECG and echocardiographic measurements the echocardiographs were performed before the ECGs, 
but where the schedule did not permit this, the findings of the ECG were unknown to the echocardiographer.

\section{Definitions adopted for this study}

1. Definition of hypertension is systolic blood pressure $\geq 140$ and/or diastolic blood pressure $\geq 90 . \mathrm{mmHg}$ in subjects who are not taking antihypertensive medication.

2. Overall Obesity is Body Mass Index (BMI) $\geq 30 \mathrm{~kg} / \mathrm{m}^{2}$.

3. Central Obesity or High Waist Hip Ratio (WHR) is WHR > 0.9 for males and $>0.8$ for females.

4. Electrocardiographic LVH Criteria

a) Sokolow and Lyon: $\mathrm{SV}_{1}+\mathrm{RV}_{5}$ or $\mathrm{RV}_{6}$ $>35 \mathrm{~mm}$

b) Minnesota: $R V_{5}$ or $\mathrm{RV}_{6}>26 \mathrm{~mm}$

c) Araoye: $\mathrm{SV}_{2}+\mathrm{RV}_{6}>40 \mathrm{~mm}$ (for males)

$\mathrm{SV}_{2}+\mathrm{RV}_{6}>35 \mathrm{~mm}$ (for females)

d) Wolff $\mathrm{SV}_{1}+\mathrm{RV}_{5}$ or $\mathrm{RV}_{6}>30 \mathrm{~mm}$

5. Echocardiographic LVH Criteria

Penn convention / Formula: Left ventricular mass (PLVM) (g)

$=1.04\left\{\left(\right.\right.$ IVSTD + LVPWTD + LVEDD $^{3}-$

LVEDD $\left.^{3}\right\}-13.6$

IVSTD - Interventricular septal thickness at enddiastole

LVPWTD - Left ventricular posterior wall thickness at end-diastole

Penn left ventricular mass indexed to body surface area (PLVMI) $\left(\mathrm{g} / \mathrm{m}^{2}\right)$

Body Surface Area $\left(\mathrm{m}^{2}\right)=\sqrt{ }\{$ Weight $(\mathrm{kg}) \mathrm{x}$ Height $(\mathrm{cm})\} / 3600$

Penn left ventricular mass index $(\mathrm{PLVMI})=$ PLVM / BSA

Penn left ventricular echocardiographic LVH defined by:

PLVMI $>125 \mathrm{~g} / \mathrm{m}^{2}$ in males and PLVMI $>110$ $\mathrm{g} / \mathrm{m}^{2}$ in females

(Compendium of ESC Guidelines 2007, 2007)

The LVH was defined as such because the prognostic value of such a limit in uncomplicated subjects with hypertension is the most widely quoted.

\section{Data Management}

Database: All subjects had a data record or collection form and double entry was used. Data was exported or transferred into Stata version 6.0 statistical package, Excel, and SPSS for statistical analysis and graphics.

Statistical Design and Analysis: For continuous variables, the mean and standard deviation were used and were compared using standard t-test / ANOVA because the data were normally distributed. Discrete variables were analysed using Pearson chi squared test. For continuous variables, the estimates were for difference in means with $95 \%$ confidence intervals.

The Minnesota, Araoye, Sokolow and Wolff criteria which are either popular world-wide or based on African populations were studied using Penn convention formula left ventricular mass index as the gold standard to choose the criterion with the overall best accuracy for the diagnosis of LVH.

The Receiver Operating Characteristic (ROC) curves were drawn for the hypertensives and nonhypertensives using the sensitivity and $100-$ specificity per cent values. The distances of the various criteria from the top left - hand corner were measured in centimetres to the nearest $0.1 \mathrm{~cm}$.

Ethical Considerations: The study was approved by The Gambia Government / MRC Ethical Committee. Informed signed or thumb printed consent was obtained from each subject after careful explanation and consideration.

\section{RESULTS}

Two hundred and eight hypertensives (70 males) and 108 non-hypertensives (39 males) gave consent and had a complete data set and were used for analysis. The mean duration of hypertension was 8.02 years. It ranged from two weeks to forty years. There were twice as many females as males in both the hypertensive and nonhypertensive groups. Four and one of the hypertensives and non-hypertensives respectively had 
complete left bundle branch block (Complete LBBB) and were excluded from analysis. None of the participants had right bundle branch block or atrial fibrillation.

Tables 1-6 outline the results and are self explanatory. There was no significant difference between the age and height of the hypertensives and non-hypertensives. However, the weight, body mass index and systolic and diastolic blood pressures were significantly higher in the hypertensives than non- hypertensives.

There were significant differences between the two groups in all the ECG characteristics From Table 3 there were no significant differences in the LVEDD $(t=0.32)$ and LVESD $(t=-1.45)$ of the two groups.

From Table 4 there was significant Spearman rank correlation between all the ECG criteria (Minnesota, Araoye, Sokolow and Lyon and
Wolff) and Penn formula left ventricular mass index in the hypertensives. There was no significant correlation between any of the ECG criterion and ECHO left ventricular mass index in the nonhypertensives.

Validity Data: The validity data show that in the hypertensives sensitivity and specificity were highest in Wolff and Minnesota respectively and in the non-hypertensives sensitivity and specificity were highest in Wolff and Minnesota respectively.

Receiver Operating Characteristic (ROC) Curves: Figure 1 shows that in the hypertensive group Sokolow and Lyon criterion was nearest to the top left corner and from Figure 2 Wolff was nearest in the non-hypertensives.

Table 1: The clinical characteristics of the hypertensives (HBP) and non-hypertensives (Non-HBP)

\begin{tabular}{|c|c|c|c|c|}
\hline & $\begin{array}{c}\text { HBP } \\
\text { Mean (SD) }\end{array}$ & $\begin{array}{l}\text { Non-HBP } \\
\text { Mean (SD }\end{array}$ & $\begin{array}{l}\text { Difference } \\
(95 \% \text { CI })\end{array}$ & $\begin{array}{c}\mathbf{P} \\
\left(\mathrm{t} \text { or } \chi^{2} \text { test }\right)\end{array}$ \\
\hline *No of patients & 208 & 108 & & \\
\hline Age (years) & $55.2(11.6)$ & $50.4(12.1)$ & $4.8(-7.6$ to -2.1$)$ & $<0.01(\mathrm{t})$ \\
\hline *Age range (yr) & $27-85$ & $31-80$ & & \\
\hline$* \operatorname{Sex} \mathrm{M} / \mathrm{F}$ & $70 / 138$ & $39 / 69$ & & $0.90\left(\chi^{2}\right)$ \\
\hline$\% \mathrm{~F}$ & 66 & 64 & & \\
\hline Weight (kg) & $73.6(16.7)$ & $65.9(13.6)$ & $-7.7(-11.4$ to -4.0$)$ & $<0.01(\mathrm{t})$ \\
\hline Height (m) & $1.64(0.08)$ & $1.64(0.09)$ & 0.0 (-0.02 to 0.02$)$ & $0.90(t)$ \\
\hline BMI $\left(\mathrm{kg} / \mathrm{m}^{2}\right)$ & $27.5(6.3)$ & $24.5(5.4)$ & $-3.0(-4.4$ to 1.6$)$ & $<0.01(\mathrm{t})$ \\
\hline $\mathrm{SBP}(\mathrm{mmHg})$ & $148(27)$ & $116(13)$ & $-32.2(-37.7$ to -26.8$)$ & $<0.01(\mathrm{t})$ \\
\hline DBP (mmHg) & 89 (14) & $72(9)$ & $-16.8(-19.6$ to -26.8$)$ & $<0.01(\mathrm{t})$ \\
\hline BSA & $1.82(0.22)$ & $1.73(0.19)$ & $-0.09(-0.14$ to -0.04$)$ & $<0.01\left(\chi^{2}\right)$ \\
\hline *BMI ${ }^{3} 30$ & $64 / 208$ & $18 / 108$ & & $0.05\left(\chi^{2}\right)$ \\
\hline *HIGH WHR & $158 / 208$ & $62 / 108$ & & $<0.01\left(\chi^{2}\right)$ \\
\hline
\end{tabular}

$t=$ Two sample $t$ test with equal variance $\chi^{2}=$ Pearson chi squared

$P=$ statistical significance of difference BSA $\left(\mathrm{m}^{2}\right)=$ Body Surface Area

$B M I=$ Body Mass Index $B M I \geq 30\left(\mathrm{~kg} / \mathrm{m}^{2}\right)=$ General obesity

WHR (Waist Hip Ratio) HIGH WHR $=$ WHR $>0.9$ for males and $>0.8$ for females

$S B P=$ Systolic Blood Pressure DBP $=$ Diastolic Blood Pressure.

*Number

134 Journal of Science and Technology, Vol. 29, No. 1, April, 2009 


\section{DISCUSSION}

In this study standard 12-lead ECG was done in adult Gambians attending clinic with and without hypertension. The selection of patients aged 25 years and above was because essential hypertension is rarer and tends to be labile in the younger age group. The non-hypertensives showed high QRS voltages thus confirming previous reports in Africans (Matekole et al., 1993; Scott 1973; D'Arbela et al., 1972). It also confirmed the voltage difference between Caucasians and Negroes. For instance, Sokolow and Lyon (1949) observed

Table 2: The ECG characteristics of the hypertensives (HBP) and non-hypertensives (Non-HBP)

\begin{tabular}{|c|c|c|c|c|}
\hline & $\begin{array}{l}\text { HBP } \\
\text { Mean SD) }\end{array}$ & $\begin{array}{l}\text { Non-HBP } \\
\text { Mean (SD) }\end{array}$ & $\begin{array}{l}\text { Difference } \\
(95 \% \mathrm{CI})\end{array}$ & $\begin{array}{l}P \\
\left(t \text { or } \chi^{2} \text { test }\right)\end{array}$ \\
\hline *No & 208 & 108 & & \\
\hline $\mathrm{SV}_{1} \operatorname{Amp}(\mathrm{mm})$ & $14.2(7.7)$ & $10.9(5.0)$ & $\begin{array}{r}-3.2(-4.9 \text { to }- \\
1.61)\end{array}$ & $<0.01(\mathrm{t})$ \\
\hline $\mathrm{SV}_{2} \mathrm{Amp}(\mathrm{mm})$ & $14.7(8.6)$ & $12.9(5.9)$ & $-1.8(-3.6$ to -0.0$)$ & $<0.01(\mathrm{t})$ \\
\hline $\mathrm{RV}_{5} \mathrm{Amp}(\mathrm{mm})$ & $21.6(9.7)$ & $15.9(5.2)$ & $-5.2(-7.2$ to 3.2$)$ & $<0.01(\mathrm{t})$ \\
\hline $\mathrm{RV}_{6} \mathrm{Amp}(\mathrm{mm})$ & $16.1(8.1)$ & $11.7(3.9)$ & $-4.4(-6.0$ to -2.8$)$ & $<0.01(\mathrm{t})$ \\
\hline$* \mathrm{RV}_{5}$ or $\mathrm{RV}_{6}$ & 54 / 208 & $2 / 108$ & & $<0.01\left(\chi^{2}\right)$ \\
\hline$>26(\mathrm{~mm})$ & $(26.3 \%)$ & $(1.9 \%)$ & & \\
\hline$* \mathrm{SV}_{2}+\mathrm{RV}_{6}>45(\mathrm{~mm})$ & $50 / 208$ & $5 / 108$ & & $<0.01\left(\chi^{2}\right)$ \\
\hline $\mathrm{SV}_{2}+\mathrm{RV}_{6}>42(\mathrm{~mm})$ & $(24.1 \%)$ & $(4.7 \%)$ & & \\
\hline$* \mathrm{SV}_{1}+\mathrm{RV}_{5}$ or & 88 / 208 & $15 / 108$ & & $<0.01\left(\chi^{2}\right)$ \\
\hline $\mathrm{RV}_{6}>35(\mathrm{~mm})$ & $(42.5 \%)$ & $(13.9 \%)$ & & \\
\hline$* \mathrm{SV}_{1}+\mathrm{RV}_{5}$ or & $119 / 208$ & $39 / 108$ & & $<0.01\left(\chi^{2}\right)$ \\
\hline $\mathrm{RV}_{6}>30(\mathrm{~mm})$ & $(57.5 \%)$ & $(36.8 \%)$ & & \\
\hline $\begin{array}{l}S V_{1} A m p=S V_{1} \\
R V_{5} \text { Amp }=R V_{5} \\
* \text { Number }\end{array}$ & $\begin{array}{l}S V_{2} A m p \\
R V_{6} A m p\end{array}$ & $\begin{array}{l}S V_{2} A m \\
R V_{6} A m\end{array}$ & $\begin{array}{l}\text { ude } \\
\text { ude }\end{array}$ & \\
\hline
\end{tabular}

Table 3: The echocardiographic characteristics of hypertensives (HBP) and Nonhypertensives (Non-HBP)

\begin{tabular}{|c|c|c|c|c|}
\hline & $\begin{array}{c}\text { HBP } \\
\operatorname{Mean}(\mathrm{SD})\end{array}$ & $\begin{array}{l}\text { Non-HBP } \\
\text { Mean (SD) }\end{array}$ & $\begin{array}{c}\text { Difference } \\
(95 \% \text { CI })\end{array}$ & $\begin{array}{c}P \\
\left(t \text { or } \chi^{2} \text { test }\right)\end{array}$ \\
\hline$*$ No & 208 & 108 & & \\
\hline LVPWTD (mm) & $12.0(2.0)$ & $10.2(2.0)$ & $-1.8(-2.5$ to -1.1$)$ & $<0.01(\mathrm{t})$ \\
\hline IVSTD (mm) & $13.0(3.2)$ & $11.0(2.8)$ & $-2.0(-2$ to $8-1.2)$ & $<0.01(\mathrm{t})$ \\
\hline LVEDD (mm) & $42.0(7.1)$ & $42.9(5.3)$ & $0.9(-0.6$ to 0.2$)$ & $0.32(\mathrm{t})$ \\
\hline LVESD (mm) & $27.7(74)$ & $27.1(5.2)$ & $-0.6(-2.2$ to 1.0$)$ & $0.45(\mathrm{t})$ \\
\hline PLVM (g) & $234(116)$ & $182(64)$ & $-52(-76$ to -28$)$ & $<0.01(\mathrm{t})$ \\
\hline PLVMI (g/m²) & $128.7(66.3)$ & $104.7(30.7)$ & $-24.0(-37.5$ to -10.30$)$ & $<0.01(\mathrm{t})$ \\
\hline *PLVMI LVH & $99 / 208$ & $30 / 108$ & & $<0.01\left(\chi^{2}\right)$ \\
\hline (Prevalence) & $(47.5 \%)$ & $(27.8 \%)$ & & \\
\hline
\end{tabular}

*Number 
mean $\mathrm{RV}_{5}$ of $11.8 \mathrm{~mm}$ in normal whites as compared with $15.9 \mathrm{~mm}$ in non-hypertensives in this study (Table 2). This difference may be explained by factors associated with development or a myocardial disease at an early or residual stage as suggested by Betrand, et al., (1995). Araoye, (1998) in a matched study in Nigerians with 288 hypertensives and 340 controls had even higher mean $\mathrm{RV}_{5}$ of $18.2 \mathrm{~mm}$ (male) and $15.5 \mathrm{~mm}$ (female). In this study, $15.8 \mathrm{~mm}$ (male) and 16.0 $\mathrm{mm}$ (female) were obtained. The difference between this study and Araoye's may be explained by differences in body size or case selection. Araoye's hypertensives were referrals and the controls were asymptomatic healthy subjects,

Table 4: Correlation between ECG criteria and Penn formula left ventricular mass index (PLVMI) in the hypertensives (HBP) and non-hypertensives(Non-HBP)

\begin{tabular}{lcccc}
\hline \multirow{2}{*}{ Criteria } & \multicolumn{2}{c}{ Spearman rank correlation (rho) } & \multicolumn{2}{c}{ P } \\
& HBP & Non-HBP & HBP & Non-HBP \\
\hline Minnesota & 0.34 & 0.13 & $<0.01$ & 0.20 \\
Araoye & 0.30 & 0.07 & $<0.01$ & 0.49 \\
Sokolow & 0.32 & 0.06 & $<0.01$ & 0.54 \\
Wolff & 0.25 & 0.10 & $<0.06$ & 0.33 \\
\hline
\end{tabular}

Table 5: Validity data of the ECG criteria with Penn Formula as the gold standard in the hypertensives and non-hypertensives

\begin{tabular}{lrrrr}
\hline \multicolumn{1}{c}{ Hypertensives } & $\begin{array}{c}\text { Minnesota } \\
(\mathbf{9 5 \%} \text { CI) }\end{array}$ & $\begin{array}{c}\text { Araoye } \\
\text { (95\% CI) }\end{array}$ & $\begin{array}{c}\text { Sokolow } \\
(\mathbf{9 5 \%} \text { CI })\end{array}$ & $\begin{array}{c}\text { Wolff } \\
\text { (95\% CI) }\end{array}$ \\
\hline Sensitivity (\%) & 39.8 & 35.2 & 56.8 & 68.2 \\
(True positive rate) & $(29.9-50.5)$ & $(25.5-4.2)$ & $(45.8-67.2)$ & $(57.3-77.5)$ \\
Specificity (\%) & 87.7 & 85.9 & 71.4 & 53.1 \\
(True negative rate) & $(78.8-92.8)$ & $(77.1-91.8)$ & $(61.3-79.9)$ & $(42.8-61.3)$ \\
100- Specificity (\%) & 12.7 & 14.1 & 28.6 & 46.9 \\
(False positive rate) & & & & \\
Non-hypertensives & & & & \\
Sensitivity (\%) & 6.9 & 7.1 & 14.3 & 42.9 \\
(True positive rate) & 100 & $(1.2-25.0)$ & $(4.7-33.6)$ & $(25.0-62.6)$ \\
Specificity (\%) & $(1.2-24.2)$ & 95.9 & 86.5 & 66.2 \\
(True negative rate) & $(93.9-100)$ & $(87.8-98.8)$ & $(76.1-93.0)$ & $(54.2-76.5)$ \\
100- Specificity (\%) & 0 & 4.1 & 13.5 & 33.8 \\
(False positive rate) & & & & \\
\hline
\end{tabular}

Table 6: Receiver operating characteristic curve measurements

\begin{tabular}{llcccc}
\hline Criteria & & Minnesota & Araoye & Sokolow & Wolff \\
\hline \multirow{2}{*}{ Measurements $(\mathrm{cm})$} & HBP & 7.9 & 8.5 & 6.6 & 7.3 \\
& Non-HBP & 12.0 & 12.0 & 11.1 & 8.5 \\
\hline
\end{tabular}

136 Journal of Science and Technology, Vol. 29, No. 1, April, 2009 
An ROC curve for sensitivity and 100-spe sificity value sin LVH and HBP

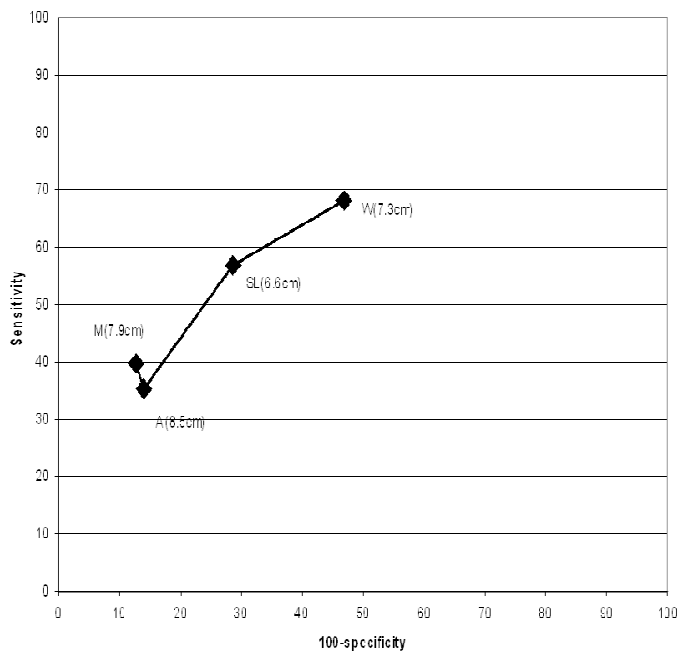

Figure 1: An ROC for sensitivity and 100specificity values in LVH and HBP

An ROC curve for sensitivity and 100-spe cificity values in LVH in non HBP

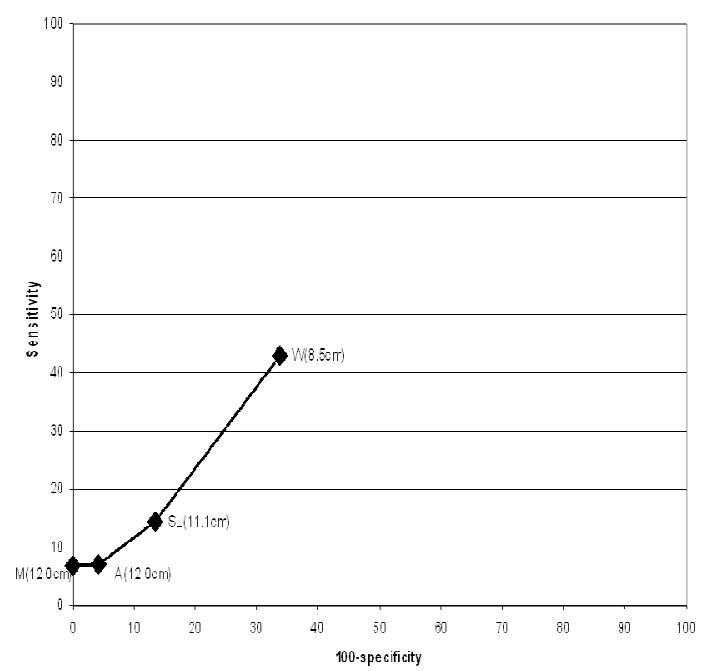

Figure 2: An ROC for sensitivity and 100specificity values in $\mathrm{LVH}$ in non HBP while in this study the subjects were enrolled from routine clinics.

$\mathrm{SV}_{1}+\mathrm{RV}_{5}$ or $\mathrm{RV}_{6}>35 \mathrm{~mm}$, a popular code for LVH among the Whites (Betrand, 1995) achieved $100 \%$ specificity in the normal Whites but only $32 \%$ sensitivity in their HBPs with LVH (Murphy et al., 1984). The following criteria were proposed by Araoye, (1996) using the 12 lead system:
1. $\mathrm{SV}_{2}+\mathrm{RV}_{6}>40 \mathrm{~mm}(4.0 \mathrm{mV})$ (male)
$\mathrm{SV}_{2}+\mathrm{RV}_{6}>35 \mathrm{~mm}(3.5 \mathrm{mV})$ (female)

2. Flat or inverted $\mathrm{T}$ waves ("Strain pattern") in $\mathrm{V}_{5}$ or $\mathrm{V}_{6}$

3. $\mathrm{R}_{1}>12 \mathrm{~mm}(1.2 \mathrm{mV})$

The cumulative sensitivity and specificity were $80 \%$ and $91 \%$ respectively for males $77 \%$ and $89 \%$ respectively for females. The overall performance for the 12 lead system is a sensitivity of $78.5 \%$ with $91.2 \%$ specificity. In this study, $48.5 \%$ of the hypertensives and $14.2 \%$ of the nonhypertensives had $\mathrm{SV}_{1}+\mathrm{RV}_{5}$ or $\mathrm{RV}_{6}>35 \mathrm{~mm}$. And the sensitivity and specificity using the Sokolow and Lyon criterion were $61.9 \%$ and $66.1 \%$ respectively. The higher sensitivity and specificity observed by Araoye may be ascribed to its cumulative system.

Katibi, in his dissertation to the West African College of Physicians found a much higher prevalence of ECG LVH for Sokolow and Lyon (71.7 $\%$ ) and Araoye (56.7 \%) in hypertensives as compared to $(42.5 \%)$ and $(24.1 \%)$ respectively obtained in this study (Table 2).

Therefore, Minnesota, Araoye, Sokolow and Wolff criteria which are either popular worldwide or based on African populations were further studied using Penn convention or formula left ventricular mass index as the gold standard to choose the criterion with the overall best accuracy for the diagnosis of $\mathrm{LVH}$.

In this study as compared to the two above, a larger sample size was used (hypertensives $\mathrm{n}=208$, non-hypertensives $n=108$ ). Penn convention for left ventricular mass indexed to body surface area 
(PLVMI) with cut-off for echocardiographic LVH as PLVMI > $125 \mathrm{~g} / \mathrm{m}^{2}$ for males and $110 \mathrm{~g} /$ $\mathrm{m}^{2}$ for females were adopted. The prevalence of echocardiographic LVH was $47.5 \%$ and $27.8 \%$ in the hypertensives and non-hypertesives respectively. Significant correlation was found between the ECG criteria and echocardiography.

Test Performance of various ECG criteria for LVH: In this study Wolff reached the highest sensitivity in both the hypertensives $(68.2 \%)$ and the non-hypertensives (42.9\%). Specificity was highest by Minnesota in both the hypertensives $(85.5 \%)$ and the non-hypertensives (100\%). From the receiver operating characteristic curve (Figure 1) Sokolow-Lyon is nearest $(6.6 \mathrm{~cm})$ to the top left-hand corner in the hypertensives and from Figure 2 Wolff is nearest $(8.5 \mathrm{~cm})$ to the top left - hand corner. Sokolow and Wolff therefore, achieved the best overall accuracy in the hypertensives and non-hypertensives respectively. But the sensitivity was slightly above $50 \%$ and the specificity was also slightly below $80 \%$.

\section{CONCLUSION}

All the four evaluated electrocardiographic criteria (Sokolow and Lyon, Minnesota, Araoye and Wolff) correlated with echocardiographic left ventricular mass index in the diagnosis of left ventricular hypertrophy in the systemic hypertensive patients but not in the non-hypertensive patients.

Sokolow and Lyon criterion achieved the best overall accuracy in the electrocardiographic diagnosis of left ventricular hypertrophy in the adult Gambian hypertensive and Wolff in the nonhypertensive.

\section{RECOMMENDATIONS}

The traditional interpretation of electrocardiogram is valuable and its use should be continued in the work-up of subjects with systemic hypertension. Sokolow and Lyon electrocardiographic criterion for the diagnosis of left ventricular hypertrophy is recommended in hypertensives but the Wolff criterion should be preferred if the patient is non-hypertensive. Other simple criteria e.g. $\mathrm{RV}_{6}>18 \mathrm{~mm}$ or the Cornell, could be evaluated in further studies to improve the sensitivity of Sokolow and Lyon criterion which was slightly above $50 \%$.

More aggressive control of hypertension in the adult Gambian should be given a priority. Drugs with good left ventricular regression efficacy, such as the angiotensin converting enzyme inhibitors should be more widely used.

\section{ACKNOWLEDGEMENTS}

This study was funded by the Medical Research Council (MRC), UK. We acknowledge that with great gratitude. We are grateful for the support of the Royal Victoria Teaching Hospital (RVTH), for the co-operation of the study participants, for the hard work of the field workers and the support from MRC Support Service. We are also grateful to Dr. Hilton Whittle, Prof. J. W. Acheampong and Dr. Alieu Gaye for their ideas, keen interest and help. Our sincere gratitude goes to Dr. Aliu O. Akano and Mr. Winston Banya for their echocardiography and statistical assistance respectively. This study would never have materialised without the help of the Ghanaian community at the MRC, led by Mr. Ben Sam. For their brotherly love and moral support we remain grateful.

\section{REFERENCES}

Akinkugbe, O.O. (1990). Epidemiology of cardiovascular disease in developing countries. Journal of Hypertension. 8: S233-S238.

Amoah, A.G.B. (2003). Hypertension in Ghana: a cross-sectional community prevalence study in Greater Accra. Ethn Dis. 13: 310-315.

Attah, E.B., Falase, A.O. (1997). Large flabby hearts in hypertension. Am Heart J. 94: 189195.

Araoye, M.A. (1996). Left Ventricular Hypertrophy by Electrocardiography: A Code System Applicable to Negroes. The Nigerian Postgraduate Medical Journal. 3: 92-97. 
Araoye, M.A. (1998). The Orthogonal and 12 lead ECG in adult negroes with systemic hypertension. Comparison with age-matched control. WAJM. 17(3): 157-164.

Betrand, D. (1995). Is electrocardiogram different in healthy black men compared with healthy white men? Tropical Cardiology. 2: 83.

Binder, E. (1961). Cardiovascular disease in Accra (Ghana) as suggested by an analysis of post-mortem results. West Afr Med J. 10: 158 $-170$

Cappuccio, F.P., Micah, F.B., Emmett, L., Kerry, S.M., Antwi, S., Martin-Peprah, R., Phillips, R.O., Plange-Rhule, J., Eastwood, J.B. (2004). Prevalence, detection, management and control of hypertension in Ashanti, West Africa. Hypertension. 43(5): 1017-22.

Compendium of European Society of Cardiology Guidelines 2007. (2007). Pp 19.

D’Arbela, P.G., Basile, U., Nloka, J.M. (1972). Electrocardiographic changes in systemic hypertension in Ugandan Africans. E Afr med J. 49: 171.

Feacham, R., Kjellstrom, T., Murray, C.J.L., Over, M., Philips, M.A. (1991). The Health of Adults in The Developing World, World Bank, New York, 1991.

Hammond, I.W., Devereux, R.B., Alderman, M.H., Lutas, E.M., Spitzer, M.C., Crowley, J.S., Laragh, J.H. (1986). The prevalence and correlates of echocardiographic left ventricular hypertrophy among employed patients with uncomplicated hypertension. J Am Coll Cardiol. 7: 639-650.

Kaufman, J.S., Barkey, N. (1993). Hypertension in Africa: an overview of prevalence rates and causal risk factors. Ethn Dis. 3: S83-101.

Levy, D., Garrison, R.J., Sarge, D.D., Kannel, W.B., Castelli, W.P. (1990). Prognostic implications of echocardiographical determined left ventricular mass in the Framingham
Heart Study. New Engl J Med 322: 15611566.

Matekole, M., Affram, K., Lee, S.J., Howle, A.J., Michael, J., Adu, D. (1993). Hypertension and end-stage renal failure in tropical Africa. J Hum Hypertens. 7: 443-446.

Mayet, J., Shahi, M., Foale, R.A., Poulter, N.R., Sever, P.S.., McG Thom, S.A. (1994). Racial differences in cardiac structure and function in essential hypertension. $\mathrm{Br}$ Med $J$. 308:1011-1014.

Mosley, W.H., Bobadilla, J., Jamison, D.T. (1993). The Health Transition: Implications for Health Policy in Developing Countries. In: Disease Control Priorities in developing Countries (ed. Jamison DT et al.) World Bank, New York, 673-699.

Murphy, M.L., Thenabadu, P.N., de Soyza, N., Doherty, J.E., Meade, J., Baker, B.J., Whittle, J.L. (1984). Re-evaluation of electrocardiogram for left, right and combined cardiac ventricular hypertrophy. Am J Cardiol. 53: 1140-7.

Plange-Rhule, J., Phillips, R., Acheampong, J.W., Saggar-Malik, A.K., Cappuccio, F.P., Eastwood, J.B. (1999) Hypertension and renal failure in Kumasi, Ghana. J Hum Hypertens. $13: 37-40$.

Pobee, J.O., Larbi, E.B., Belcher, D.W., Wurapa, F.K., Dodu, S.R. (1977). Blood pressure distribution in a rural Ghanaian population. Transactions of the Royal Tropical Society of Tropical Medicine and Hygiene. 71: 66-72.

Scott, R.C. (1973). Ventricular hypertrophy. Cardiovascular Clinics. 5: 219-253.

Sokolow, M., Lyon, T.P. (1949). The ventricular complex in left ventricular hypertrophy as obtained by uni-polar precordial and limb leads. Am Heart J. 54: 689-694.

Swai, A.B., McLarty, D.G., Kitange, H.M., Kilima, P.M., Tatalla, S., Keen, N., Chuwa, 
L.M., Alberti, K.G. (1993). Low prevalence of risk factors for coronary heart disease in rural Tanzania. International Journal of Epidemiology. 22: 651-659.

World Bank. World Development Report (1993). Investing in Health. Oxford University Press for the World Bank. New York, 1993.

140 Journal of Science and Technology, Vol. 29, No. 1, April, 2009 